\title{
A GENETIC STUDY OF NEONATAL OBSTRUCTIVE JAUNDICE
}

\author{
BY \\ DAVID DANKS* and MARTIN BODIAN \\ From the Medical Research Council, Clinical Genetics Research Unit, Institute of Child Health, \\ and the Department of Morbid Anatomy, The Hospital for Sick Children, Great Ormond Street, London
}

(RECEIVED FOR PUBLICATION JANUARY 29, 1963)

Clarification of the problem of jaundice in the neonatal period began with the discovery of foetomaternal rhesus incompatibility as the usual cause of haemolytic disease of the newborn. After this, the group of infants in whom the jaundice is of obstructive type, with pale stools and bile in the urine, received more attention, and it was soon realized that not all such infants suffered from atresia of the main bile-ducts. In 1952 Craig and Landing described the characteristic histological appearance of the liver in cases with patent bileducts, and the disease has become known as 'neonatal giant cell hepatitis'. Since then various authors have accepted the separation of this disease entity on anatomical and histological grounds, while others have felt that the histological features may be mimicked by other diseases affecting the liver in the foetal or newborn period, of varied causes such as rhesus incompatibility, cytomegalic inclusion cell virus, pyaemic infection or pylephlebitis. It is certainly true that giant cell change may be seen in many of these conditions or in biliary atresia, but consideration of other histological features seems to allow the definition of a group of cases apart from these causes.

Biliary atresia may affect any level in the biliary tree, and one newly recognized form involving only the small interlobular radicles exhibits a characteristic clinical course and histological pattern-intrahepatic biliary atresia.

Craig and Landing, and most workers since them, have assumed that 'neonatal hepatitis' is due to the infection of the foetus in utero by the virus of infectious hepatitis or of serum hepatitis. Over the years the emphasis has been on the latter virus as the more likely causative agent, and a maternal carrier state has been considered a satisfactory explanation of the often observed occurrence of

* Research Fellow from the Royal Children's Hospital, Melbourne, Australia, at tached to this Unit. several cases within a sibship. However, in 1958, Hsia, Boggs, Driscoll and Gellis pointed out that in some families with several affected children normal children were born between affected ones, and they emphasized the difficulty of explaining this in the above manner. They calculated the proportion of affected children in 59 families and found $p=0 \cdot 260 \pm 0.076$, and so suggested an autosomal gene in homozygous form as the cause. Unfortunately their cases were drawn from several sources and included three families reported by others because of striking familial incidence, so this estimate cannot be considered valid. Also, in some of their index cases the diagnosis was not adequately established.

In studying further the possibility of a genetic factor in neonatal hepatitis it was thought worth while also to collect information about cases of biliary atresia. These have provided useful control data.

\section{Case Material and Criteria of Definition of the Diseases}

At The Hospital for Sick Children, Great Ormond Street, in the years 1945 to 1961 inclusive, a definitive diagnosis was made in 110 cases of neonatal obstructive jaundice. In 58 cases the diagnosis was atresia of the major bile-ducts (extrahepatic biliary atresia), in seven, intrahepatic biliary atresia and in 45 'neonatal hepatitis'. In addition five cases were considered to have 'neonatal hepatitis' although they did not have jaundice within the first month of life. An attempt was made to trace the families of all these cases: we were successful in 47 , seven and 45 instances respectively, and the reasons for the failure to trace the remaining 16 families are not likely to influence the results based on the findings. In all the families traced, genetic data were obtained, both parents were questioned about past hepatitis and the mothers were asked about transfusions or 


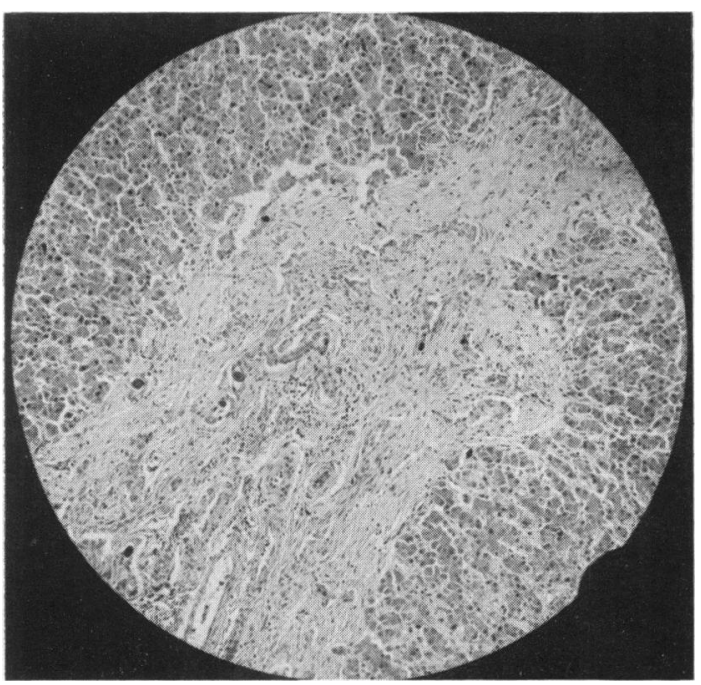

FIG. 1.-Photomicrograph of a portal area in the liver of a case of extrahepatic biliary atresia ( $\times 55)$.

injections of types especially likely to transmit serum hepatitis. A history of illnesses during the relevant pregnancy was also sought.

The clinical history in cases of neonatal obstructive jaundice of all types is most often of the onset of jaundice within the first one to two weeks of life, preceded by the passage of pale-coloured stools and of dark urine. In some infants a haemorrhagic tendency is marked, and these are usually suffering from 'neonatal hepatitis'. The bleeding may be into the skin, from the umbilicus, visceral or cerebral; indeed, one case presented with, and died of, bleeding without ever being jaundiced. Biochemical investigations show bilirubinuria and absence of stercobilin from the stools, but are rarely helpful in establishing the exact diagnosis; however, a very high level of serum glutamic pyruvic transaminase (above $400 \mu$ moles pyruvate $/ 100 \mathrm{ml}$. serum/hour) is suggestive of 'neonatal hepatitis'. Ultimately the diagnosis rests on demonstrating the presence or absence of patent bile-ducts: in this series this was achieved by operative cholangiography, by operative inspection or at autopsy, and examining sections of liver tissue histologically. Both these criteria were used in every case in this series.

The examination of bile-ducts at operation can be very difficult, and this evidence alone was often shown to be inadequate, especially in the earlier cases of this series.

The histological feature which is diagnostic of extrahepatic biliary atresia is the presence of proliferation of the interlobular portal bile-ducts and

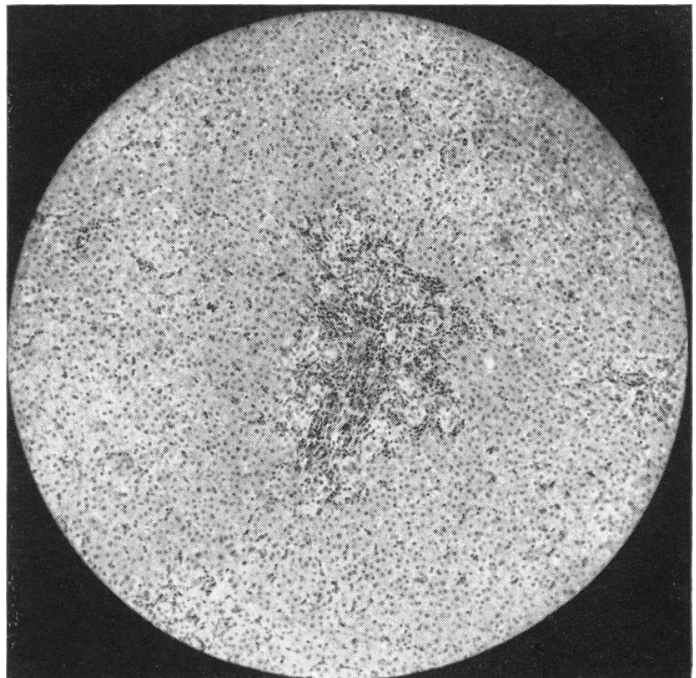

FIG. 2.-Photomicrograph of a portal area and the surrounding liver parenchyma from a case of intrahepatic biliary atresia $(\times 55)$.

the distension with bile of some or many of these (Fig. 1). Inflammatory cells may or may not be present, and fibrous tissue is always increased in the portal tracts; multinucleate giant parenchymal cells are a variable feature. In intrahepatic biliary atresia (Fig. 2), diagnosis in early infancy is difficult, but sections show proliferation of portal bile-duct radicles which are empty or even devoid of a lumen, around which there is a marked cellular infiltration. The other characteristic feature of almost total absence of the portal bile-ducts is frequently not seen until a later stage in the disease. Portal fibrous tissue is often not increased in this phase. Again giant cells may be seen.

In 'neonatal hepatitis' there is retention of bile in the liver parenchymal cells and canaliculi (as there is in both types of biliary atresia) but there are no proliferative changes in the bile-ducts of the portal tracts and they do not contain bile. Cellular infiltration of the portal tracts is variable, and often many of the cells are haemopoietic. Some degree of multinucleate giant cell change is always present but it may be slight or so gross as to involve most of the parenchymal cells (Fig. 3). Often these giant cells have a granular cytoplasm and an illdefined cell boundary; however, frank cell necrosis has been seen only in sections obtained after death caused by massive haemorrhage.

For the purpose of this study three types of cases of 'neonatal hepatitis' were recognized-33 cases showed typical clinical features and pathology ('typical neonatal hepatitis'), seven presented with 


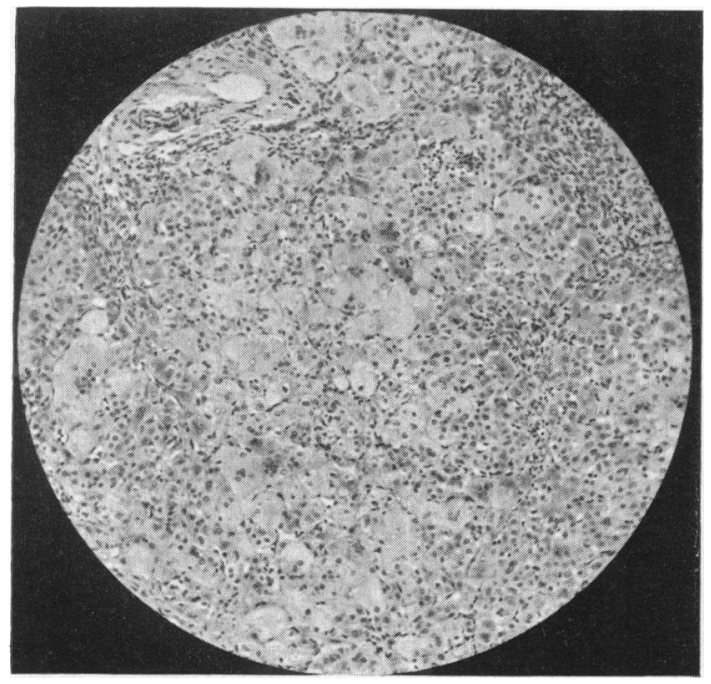

FIG. 3.-Photomicrograph of a liver lobule showing the changes seen in an infant with 'neonatal hepatitis' ( $x 230)$.

the usual symptoms in infancy, but no histological examination was made until some years later when only a non-specific multilobular cirrhosis could be seen ('clinical neonatal hepatitis'), and in five the clinical features were late in onset, or consisted only of bleeding, yet the histology was typical ('histological neonatal hepatitis').

The natural course of extrahepatic biliary atresia is invariably fatal, although survival for several years may occur. In a proportion of the cases ( 1 in 10 to 1 in 20) the atresia is localized to the common bile-duct, and surgical anastomosis may sometimes result in cure. In no case in this series was a cure achieved. Intrahepatic biliary atresia has not been known long enough for one to establish its course, but six of our seven cases are still alive, one girl being 14 years old and another 7 years old. These children show hypercholesterolaemic xanthomatosis and brown skin pigmentation with a serum bilirubin level only a little elevated $(1 \mathrm{mg} . / 100 \mathrm{ml}$.) and have normal coloured stools. The mechanism by which they excrete their bile is not known.

In 'neonatal hepatitis' there is considerable risk of death in early infancy from intercurrent infection 'gastro-enteritis, pneumonia, meningitis), or haemorhage, and operative intervention may greatly ncrease this hazard. However, in the past seven vears, since a very limited operative exposure cholangiography and biopsy but no attempt to lissect out the bile-ducts) has been employed as an nitial step, there has been only one death associated vith operation. The infant who survives the first

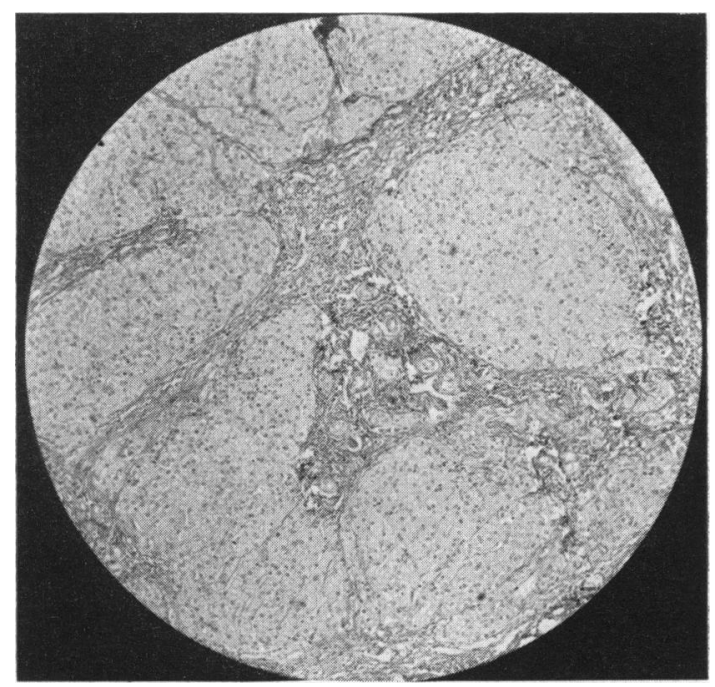

FIG. 4.-Photomicrograph of a section of liver of a child who suffered from 'neonatal hepatitis'. The changes are now those of multilobular cirrhosis $(\times 55)$.

months of life may cease to be jaundiced by 4-6 months of age and apparently recover completely: we have shown normal liver histology in three cases, and three other children, now over 12 years old, are normal to clinical and biochemical examinations, but in them we do not have biopsy proof of recovery. In many infants, however, the jaundice never goes, or fades only to return later along with other manifestations of cirrhosis (large liver and spleen, bleeding from oesophageal varices, ascites and oedema, liver failure) which later cause death (Table 1). In our series manifestations of cirrhosis have always been apparent by the age of 5 years, and death at 11 to 12 years has been very common and due to bleeding plus liver failure. We have five cases with histological changes ranging from slight fibrosis to moderate cirrhosis (Fig. 4), and two who are clinically and biochemically normal but less than 3 years old; in all these the prognosis is uncertain.

It seems that about one-third of our cases are likely to recover fully. However, this may be too gloomy a prognosis, for some of those who died after extensive surgery in earlier years might today recover, and our insistence on biopsy proof excludes some children seen with a similar but mild illness which might well be this disease. Hsia et al. (1958), including 15 such cases in their studies on the prognosis in this disease and also regarding as recovered some young infant who might well present later with cirrhosis, suggested that two-thirds of the cases of this disease recover fully. The truth probably lies between these estimates. 
TABLE 1

OUTCOME OF THE DISEASE IN INDEX CASES OF 'NEONATAL HEPATITIS'

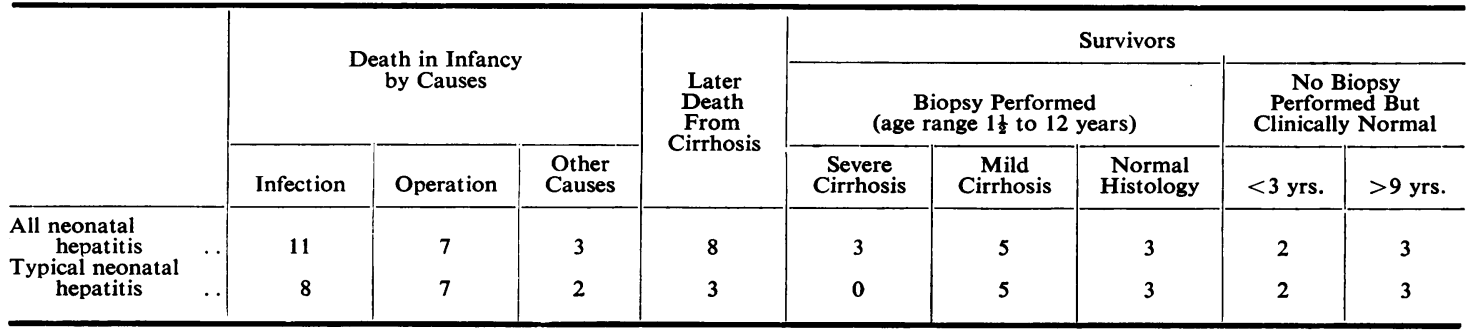

Frequency in the General Population

No figure is known for the frequency of any of the three diseases, and the pattern of referral of children to The Hospital for Sick Children varies from disease to disease and makes accurate assessment difficult. About three to four new cases each of extrahepatic biliary atresia and 'neonatal hepatitis' present annually. If one compares this figure with the numbers of new cases of certain diseases whose frequency in the community is known, such as Down's syndrome (1 in 620, Carter and MacCarthy, 1951 ) or pyloric stenosis (1 in 333, MacMahon, Record and McKeown, 1951), and remembers that rare diseases tend to be especially selected for referral to this hospital, one can derive a very approximate figure for the frequency of the diseases under consideration. It seems that the frequency of extrahepatic biliary atresia or of 'neonatal hepatitis' of sufficient severity to be diagnosed with certainty is of the order of 1 in 25,000 live births. Intrahepatic biliary atresia must be very rare.

\section{Twins}

There were none in this series.

\section{Consanguinity}

Among the parents of the cases of extrahepatic and of intrahepatic biliary atresia none were blood relatives. However, in four of the 44 families
(45 index cases) containing a case of 'neonatal hepatitis', the parents were related. In two the parents were first cousins. The relationships of the parents in these families were: Case 9, the father's mother and the mother's mother were sisters; Case 14, the father's mother and the mother's father were siblings; Case 13, the father's father and the mother's maternal grandmother were siblings; and Case 22, the father's father and the mother's maternal grandfather were half brothers. (The case numbers refer to Appendix 1.)

There has been no survey of the frequency of consanguineous marriage in south-east England in recent years, but it is very unlikely that the total for all degrees of close relationship is greater than 4 per 1,000 unions. Whatever the exact figure, our finding is clearly unlikely to be due to chance.

\section{Sex Ratio}

The sex ratio for the index cases of the three diseases is shown in Table 2. Although there is an excess of male over female in the cases of 'neonatal hepatitis', this does not reach significance at the $5 \%$ level. The same order of excess of affected males was noted by Hsia et al. (1958). Combining these series is not valid because of the different diagnostic criteria used, but it seems that there may be a true tendency for male infants to be affected more often than female.

TABLE 2

SEX OF INDEX CASES

\begin{tabular}{|c|c|c|c|c|c|c|c|c|c|}
\hline & & & & E.H.A. & I.H.A. & All N.H. & $\begin{array}{l}\text { *Typical } \\
\text { N.H. }\end{array}$ & $\begin{array}{l}\text { *Clinical } \\
\text { N.H. }\end{array}$ & $\begin{array}{c}\text { *Histological } \\
\text { N.H. }\end{array}$ \\
\hline $\begin{array}{l}\text { Male } \\
\text { Female }\end{array}$ & $\cdots$ & $\begin{array}{l}\cdots \\
\cdots\end{array}$ & $\cdots$ & $\begin{array}{l}22 \\
25\end{array}$ & $\begin{array}{l}4 \\
3\end{array}$ & $\begin{array}{l}29 \\
16\end{array}$ & $\begin{array}{l}21 \\
12\end{array}$ & $\begin{array}{l}5 \\
2\end{array}$ & $\begin{array}{l}3 \\
2\end{array}$ \\
\hline \multicolumn{3}{|c|}{ Male : Female Ratio } & $\ldots$ & 0.880 & $\dagger$ & $1 \cdot 813 \ddagger$ & $1 \cdot 750 \ddagger$ & + & $\dagger$ \\
\hline
\end{tabular}

* Defined in the text.

+ Numbers too small to calculate proportion.

$\ddagger \chi^{2}=2 \cdot 366$, D.F. $1,0 \cdot 20>p>0 \cdot 10$.
E.H.A. Extrahepatic biliary atresia

I.H.A. Intrahepatic biliary atresia.

N.H. 'Neonatal hepatitis'. 
TABLE 3

PROPORTION AFFECTED AMONG SIBLINGS OF INDEX CASES OF 'NEONATAL HEPATITIS'

\begin{tabular}{|c|c|c|c|c|c|c|c|}
\hline & & All N.H. & $\begin{array}{l}\text { *Typical } \\
\text { N.H. }\end{array}$ & $\begin{array}{l}\text { *Clinical } \\
\text { N.H. }\end{array}$ & $\begin{array}{c}\text { *Histological } \\
\text { N.H. }\end{array}$ & $\begin{array}{l}\text { Selected } \\
\text { All N.H. }\end{array}$ & $\begin{array}{c}\text { Selected } \\
\text { Typical N.H. } \ddagger\end{array}$ \\
\hline $\begin{array}{ll}\text { Number affected } & . \\
\text { Total number } & \ldots\end{array}$ & $\begin{array}{l}\cdots \\
\cdots\end{array}$ & $\begin{array}{l}12 \\
85\end{array}$ & $\begin{array}{r}8 \\
66\end{array}$ & $\begin{array}{r}1 \\
14\end{array}$ & $\begin{array}{l}3 \\
5\end{array}$ & $\begin{array}{l}12 \\
71\end{array}$ & $\begin{array}{r}8 \\
47\end{array}$ \\
\hline Proportion affected & $\cdots$ & $0 \cdot 141 \pm 0 \cdot 038 \S$ & $0.121 \pm 0.028$ & $\dagger$ & $t$ & $0 \cdot 169 \pm 0.044 \S$ & $0.145 \pm 0.048$ \\
\hline
\end{tabular}

* Defined in the text

$\dagger$ Numbers too small to calculate ratio.

\$Cases remaining after exclusions described in the text.

\section{Familial Incidence}

In the cases of extrahepatic and intrahepatic biliary atresia there was no instance of another affected person among the first or second degree relatives. In the extrahepatic type there were 90 siblings, 278 aunts and uncles and 410 first cousins all unaffected, so one can state with confidence that there is no familial tendency in this disease and thus agree with the finding of Hsia et al. (1958). Our seven cases of intrahepatic biliary atresia had 12 siblings, 43 aunts and uncles and 36 first cousins, all unaffected.

In 'neonatal hepatitis' some siblings were affected, and will now be discussed in detail; but there was no other person affected among 88 parents, six half siblings, 310 aunts and uncles and 469 first cousins. Details will be found in Appendix 1.

Incidence in Siblings. In one sibship both children are index patients, though one falls in the 'typical neonatal hepatitis' group and one in the 'clinical neonatal hepatitis' group. In six other families a second child was affected; two index cases each had two siblings affected. In these 10 siblings the diagnosis was based on histological examination of liver sections by ourselves in three, on hospital description of a typical illness in five and on a very clear description by the parents in the remaining two. Details of these cases are given in Appendix 2. One other sibling who had jaundice for two weeks after birth is not counted as affected.

If one calculates the proportion of siblings of index cases who are affected (rather than that of affected children in the whole families), allowance is made for the influence of the number of affected children in a family upon the likelihood of detecting that family. The results in the different groups of cases are shown in Table 3. In a series of cases such as this it is unrealistic to assume complete ascertainment, and calculations based on this assumption (Haldane, 1938) yield $\mathrm{p}=0.282 \pm$ 0.043 in the 'typical neonatal hepatitis' group.
As has been mentioned, various authors have suggested that the histological features of 'neonatal hepatitis' may be very closely mimicked by other and known disease entities affecting the liver. Among our index cases are five in whom such other diseases were present though we had not considered them causative-haemolytic disease of the newborn in three (Nos. 2, 25 and 28), definite infection of the umbilical vein in one (No. 21), and inclusion cell virus lesions in the kidney of a fifth (No. 27); two other cases were slightly unusual in their manifestation (Nos. 3 and 39).

As we were seeking a reason for the failure of the proportion of affected siblings of index cases to reach the 0.250 level expected on the hypothesis of causation by an autosomal gene in homozygous form, it seems worth considering that, despite adopting the strict criteria of diagnosis mentioned, we have included more than one disease entity in this series. Recalculation after exclusion of these cases brings the proportion affected among 'all cases', but not that among 'typical N.H.' cases, just closer to $\mathbf{0 . 2 5 0}$ than twice the standard error. These exclusions were the result of stringent appraisal of all clinical, biochemical and histological features of the cases, and no others can be separated by these criteria. It may be that we still have cases of more than one disease in this series, but if so, new criteria are needed to distinguish them. Of course, it is also possible that the above exclusions are artificial.

An alternative possible explanation of this deficiency of affected siblings is that not all infants homozygous for the mutant gene manifest this disease sufficiently for the diagnosis to be made. Among the index patients there is certainly wide variation in the severity of the condition, and the sex ratio mentioned could be caused by failure of manifestation in some females. Evidence, admittedly of very weak character, will be given for another possibility, namely that one or two siblings 
TABLE 4A

BIRTH ORDER OF INDEX CASES OF EXTRAHEPATIC BILIARY ATRESIA AND OF 'NEONATAL HEPATITIS' COMPARED WITH THOSE FOR BIRTHS IN THE SAME YEAR IN ENGLAND AND WALES

\begin{tabular}{|c|c|c|c|c|c|c|c|c|}
\hline & & Birth Order & 1 & 2 & 3 & 4 & $5+$ & Total \\
\hline E.H.A. & $\ldots$ & $\begin{array}{l}\text { Observed } \\
\text { Expected }\end{array}$ & $\begin{array}{l}16 \\
16 \cdot 53\end{array}$ & $\begin{array}{l}15 \\
14 \cdot 33\end{array}$ & $\begin{array}{l}7 \\
6 \cdot 65\end{array}$ & $\begin{array}{l}3 \\
3 \cdot 17\end{array}$ & $\begin{array}{l}2 \\
3 \cdot 38\end{array}$ & 44 \\
\hline All N.H. & $\begin{array}{ll}\ldots & \ldots\end{array}$ & $\begin{array}{l}\text { Observed } \\
\text { Expected }\end{array}$ & $\begin{array}{l}14 \\
17 \cdot 42\end{array}$ & $\begin{array}{l}15 \\
13 \cdot 19\end{array}$ & $\begin{array}{l}7 \\
6 \cdot 36\end{array}$ & $\begin{array}{l}5 \\
2 \cdot 92\end{array}$ & $\begin{array}{l}2 \\
3 \cdot 24\end{array}$ & +43 \\
\hline
\end{tabular}

For E.H.A. $\chi^{2}=0.53$, D.F. 3, 0.95 $>$ p $>0.90$.

For N.H. $\quad \chi^{2}=1 \cdot 39$, D.F. $3.0 \cdot 80>p>0 \cdot 70$.

TABLE 4B

MATERNAL AGE OF INDEX CASES OF EXTRAHEPATIC BILIARY ATRESIA AND OF 'NEONATAL HEPATITIS' COMPARED WITH THOSE FOR BIRTHS IN THE SAME YEAR IN ENGLAND AND WALES

\begin{tabular}{|c|c|c|c|c|c|c|c|c|}
\hline & & & Mother's Age & $15-24$ & $25-29$ & $30-34$ & $35+$ & Total \\
\hline E.H.A. & . & $\ldots$ & $\begin{array}{l}\text { Observed } \\
\text { Expected }\end{array}$ & $\begin{array}{l}10 \\
14 \cdot 88\end{array}$ & $\begin{array}{l}14 \\
14 \cdot 29\end{array}$ & $\begin{array}{r}11 \\
8.96\end{array}$ & $\begin{array}{l}9 \\
5 \cdot 87\end{array}$ & $* 44$ \\
\hline All N.H. & $\cdots$ & $\cdots$ & $\begin{array}{l}\text { Observed } \\
\text { Expected }\end{array}$ & $\stackrel{8}{13 \cdot 72}$ & $\begin{array}{l}18 \\
13 \cdot 94\end{array}$ & $\begin{array}{l}9 \\
9.03\end{array}$ & $\begin{array}{l}8 \\
6 \cdot 39\end{array}$ & 43 \\
\hline
\end{tabular}

For E.H.A. $\chi^{2}=3 \cdot 74$, D.F. $3,0 \cdot 30>p>0 \cdot 20$ For N.H. $\chi^{2}=3 \cdot 88$, D.F. $3,0 \cdot 30>p>0 \cdot 20$.
* One illegitimate child, one child of second marriage excluded.

$\uparrow$ Two illegitimate children excluded.
(Appendix 3 and Table 6) may have died of this disease on the first day of life.

\section{Birth Order and Maternal Age}

As few of the families of index cases in this series are complete, the only method available for analysis of the influence of birth order and maternal age is comparison with figures for the comparable population. The figures used for the comparison are for England and Wales and are those of the RegistrarGeneral (Table II up to 1951 and Table HH from 1952 onwards). In these tables only legitimate births are counted as index cases; from 1952 onwards stillbirths have not been included among the number of previous children, and women married more than once have been excluded. These practices have been followed with our cases. It is apparent from Table $4 \mathrm{~A}$ and $\mathrm{B}$ that there is no deviation from expectation of mean maternal age or of birth rank in extrahepatic biliary atresia or in 'neonatal hepatitis'. The number of cases of intrahepatic biliary atresia is too small for analysis.

\section{Birth Weight}

In looking through the clinical data of the index cases of 'neonatal hepatitis' it seemed that small birth weight was a feature. Analysis of the birth weights in this condition and in extrahepatic biliary atresia is shown in Table 5, and it is clear that there is a very significant lowering in the cases of neonatal hepatitis and that this is not confined to those born before the 38th week of gestation. The mean is below that found by Karn and Penrose (1951) in 13,116 consecutive births by more than four times its standard error. There is no such change in the birth weights of cases of extrahepatic biliary atresia, and there are too few cases of intrahepatic biliary atresia for analysis.

In Fig. 5 the frequencies of different birth weights are plotted in both diseases, and a curve of assumed normality based on the figures of Karn and Penrose (1951) is superimposed. The suggestion of bimodality indicated another way of seeking two disease groups among the index cases. However, the birth weights of the children of related parents and of those who had affected siblings were distributed

TABLE 5

BIRTH WEIGHT (lb.) OF INDEX CASES OF EXTRAHEPATIC BILIARY ATRESIA AND OF 'NEONATAL HEPATITIS'

\begin{tabular}{|c|c|c|c|}
\hline & & All Maturities & *Full Term Only \\
\hline $\begin{array}{l}\text { +Normal } \\
\text { E.H.A. } \\
\text { All N.H. } \\
\text { Typical N.H. }\end{array}$ & $\begin{array}{l}\cdots \\
\cdots \\
\cdots \\
\cdots\end{array}$ & $\begin{array}{l}7 \cdot 24 \\
7 \cdot 4 \pm 0 \cdot 232 \\
6 \cdot 2 \pm 0.231 \\
6.0 \pm 0.289\end{array}$ & $\begin{array}{l}7.8 \pm 0.203 \\
6.6 \pm 0.238 \\
6.5 \pm 0.325\end{array}$ \\
\hline
\end{tabular}

* Gestation time between 38 and 42 weeks.

† Data of Karn and Penrose (1951)-13,116 births. 


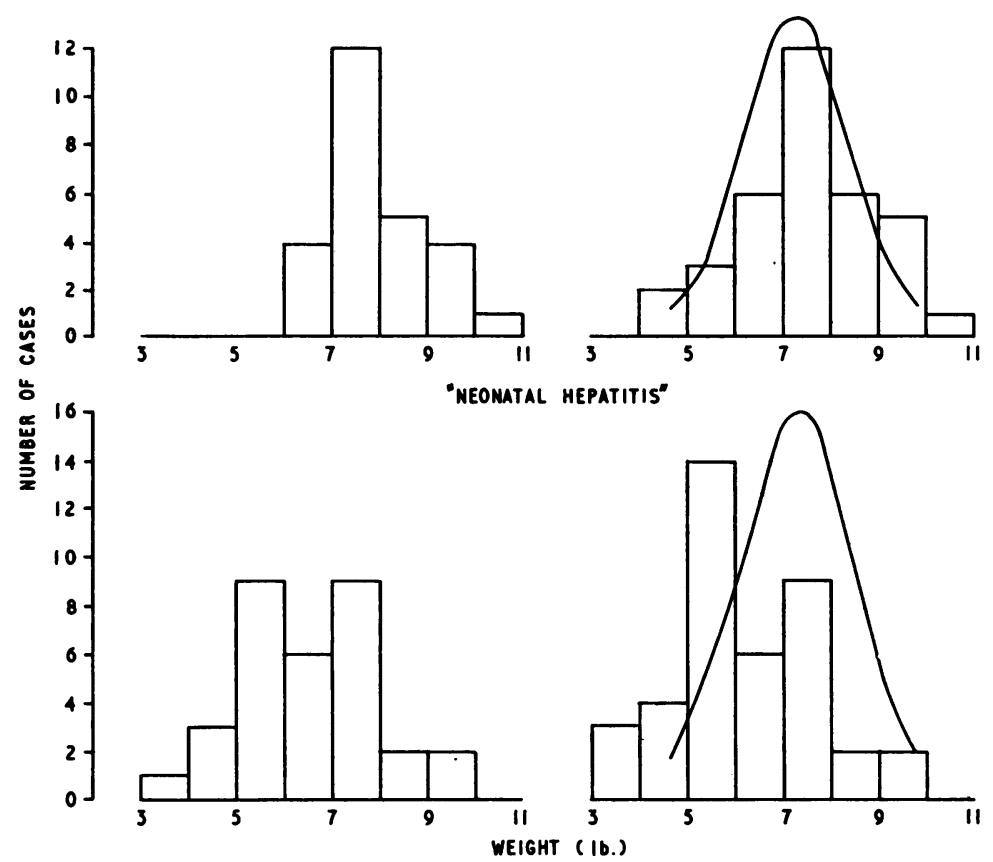

FIG. 5.-Distribution of birth weights of index cases of extrahepatic biliary atresia and of 'neonatal hepatitis'. Curve is an assumed normal one based on the data of Karn and Penrose (1951).

throughout the range found; furthermore, restricting consideration to 'typical N.H.' cases, or exclusion of those seven cases discussed before, does not alter the trend of this result.

This finding is, however, strong confirmation of the clinical impression that, in cases of 'neonatal hepatitis', function of the parenchymal liver cells is deranged during foetal life. That the damage to liver parenchyma in extrahepatic biliary atresia is mainly a postnatal event is also supported.

TABLE 6

FREQUENCY OF MISCARRIAGE AND OF +UNEXPLAINED PERINATAL DEATHS IN THE FAMILIES OF INDEX CASES OF EXTRAHEPATIC BILIARY ATRESIA AND OF 'NEONATAL HEPATITIS'

\begin{tabular}{|c|c|c|}
\hline & ${ }^{*}$ Miscarriages & $\begin{array}{l}\text { †Unexplained } \\
\text { Perinatal Deaths }\end{array}$ \\
\hline $\begin{array}{l}\text { E.H.A. } \\
\text { All N.H. } \\
\text { Typical N.H. }\end{array}$ & $\begin{array}{cc}18 / 108(16 \cdot 7 \%) \\
11 / 96 \quad(11 \cdot 5 \%) \\
8 / 75 \quad(10.7 \%)\end{array}$ & $\begin{array}{l}2 / 90(2 \cdot 2 \%) \\
5 / 85(5 \cdot 8 \%) \\
5 / 66(7.6 \%)\end{array}$ \\
\hline
\end{tabular}

* Total numbers are all pregnancies of the mothers, excluding the index cases.

$\dagger$ Total numbers are all pregnancies reaching viability, excluding index cases. There were two other perinatal deaths in the N.H. group, but the causes were known ('neonatal hepatitis' in one, haemolytic disease of the newborn in the other).

\section{Miscarriages, Stillbirths and other Deaths}

The frequency of miscarriages and of unexplained perinatal deaths (stillbirths plus neonatal deaths) in the families of the index cases of extrahepatic biliary atresia and of 'neonatal hepatitis' is shown in Table 6. It is clear that miscarriage is not unusually frequent in these families, but the five perinatal deaths among the siblings of cases of 'neonatal hepatitis' are of interest; details are given in Appendix 3. One was stillborn at 8 months' gestation, and the other four died on the first or second days of life, three being at least eight weeks premature and one being a like sex twin of a surviving unaffected child. Unfortunately these five cases were born in small nursing homes which kept no records; in no case was an autopsy performed. In view of the marked impairment of foetal nutrition suggested by the low birth weights of the cases of 'neonatal hepatitis', it is tempting to suggest that some of these perinatal deaths may represent the extreme effect of the abnormal genotype.

\section{Hepatitis in Parents}

Because of the suggestions already referred to that 'neonatal hepatitis' is the result of trans- 
placental infection with one or other of the hepatitis viruses, careful inquiry was made for a past history of hepatitis, for the occurrence of any such illness during the relevant pregnancy and for the receipt of a blood transfusion or of injections of any material given by a mass immunization type of technique (with a higher than usual risk of transfer of serum from one person to another) (Table 7). Almost all the mothers had blood samples taken at antenatal clinics-this has not been counted here, but probably carries considerable risk of serum transfer. It was felt that the mothers of cases of extrahepatic biliary atresia provided an ideal control group for these observations: in each disease the parents would have discussed with their own parents the possible cause of their infant's disease and so would have been reminded of childhood hepatitis.

\section{TABLE 7}

FREQUENCY OF A PAST HISTORY OF INFECTIOUS HEPATITIS IN MOTHERS OR FATHERS, AND OF TRANSFUSION OR OF *'MASS INJECTIONS' IN MOTHERS, OF INDEX CASES OF EXTRAHEPATIC BILIARY ATRESIA AND 'NEONATAL HEPATITIS'

\begin{tabular}{|c|c|c|c|c|}
\hline & \multicolumn{2}{|c|}{$\begin{array}{l}\text { Past History } \\
\text { of Hepatitis }\end{array}$} & \multirow{2}{*}{$\begin{array}{l}\text { Trans- } \\
\text { fusion }\end{array}$} & \multirow{2}{*}{$\begin{array}{c}\text { *'Mass, } \\
\text { Injections' }\end{array}$} \\
\hline & Mothers & Fathers & & \\
\hline $\begin{array}{ll}\text { E.H.A... } & \cdots \\
\text { All N.H. } & \\
\text { Typical N.H. }\end{array}$ & $\begin{array}{r}4 / 44 \\
+8 / 44 \\
5 / 33\end{array}$ & $\begin{array}{l}5 / 33 \\
4 / 34 \\
3 / 26\end{array}$ & $\begin{array}{l}2 / 44 \\
1 / 44 \\
1 / 33\end{array}$ & $\begin{array}{l}16 / 44 \\
19 / 44 \\
14 / 33\end{array}$ \\
\hline
\end{tabular}

* Injections given to the mother among many other persons and so especially liable to result in transfer of serum.

$\dagger$ One of these is the mother of two index cases.

We did in fact find that more of the mothers of index cases of 'neonatal hepatitis' had themselves suffered an illness diagnosed as hepatitis in the past. In most the disease had occurred more than 10 years before the birth of the affected child, and in only one (the mother of Cases 7 and 36) had any injection been given within four months before the illness. In this woman, serum or infectious hepatitis seems equally likely. The others affected were the mothers of index Cases 3, 13, 22, 27, 31, 35 and 43. In no mother in either group did any illness resembling hepatitis occur during pregnancy, and other abnormalities of pregnancy were not unduly frequent.

An increased susceptibility to hepatitis in persons heterozygous for the postulated mutant gene could explain the increased frequency of hepatitis in the past among the mothers of index cases. However, this increased frequency of hepatitis in the past was not present among the fathers (only those of index Cases 22, 26, 28 and 42 had been affected).

Transfusion or the receipt of the type of injections described was equally frequent among the mothers of index cases of both diseases.

\section{Discussion}

In extrahepatic biliary atresia our genetic findings are negative. We have found no familial incidence, a normal mean birth weight of the cases, and agreement with expectation of birth rank and maternal age. There is no recent report of this disease affecting more than one member of a family, though Sweet, in 1932, reported the occurrence in three siblings of what he describes as this disease. The evidence he gives is not sufficient to allow one to discuss the accuracy of the diagnosis, but cases of 'neonatal hepatitis' have very often been misclassified as biliary atresia.

The seven cases of intrahepatic biliary atresia provide too small a group for analysis, but the absence of any familial incidence is in keeping with other reports (Ahrens, Harris and MacMahon, 1951; Haas and Dobbs, 1958); these authors add six cases to our seven.

There is no dispute about the existence of an increased familial incidence in 'neonatal hepatitis', but there is much debate about the reason for this and about the aetiology of the disease. That inclusion cell virus infection may occasionally mimic the disease is likely (Weller, Macauley, Craig and Wirth, 1957), and it may be that other agents damaging the liver may do so. The role of the viruses of infectious hepatitis and of serum hepatitis is very difficult to prove or disprove. Unfortunately, most writers have taken as proven their causative role and only Smetana and Johnson (1955) and Hsia et al. (1958) seem to have assessed the evidence critically. The principal facts are as follows:

(1) There is undoubted evidence that serum hepatitis may be repeatedly transmitted by serum of a person, presumed therefore to be a carrier of the virus, over many (at least 10) years. During such a period the carrier state seems constant, for virtually all samples of serum are productive of disease (Stokes, Berk, Malanut, Drake, Barondess, Bashe, Wolman, Farquhar, Bevan, Drummond, Maycock, Capps and Bennett, 1954; Neefe, Norris, Reinhold, Mitchell and Howell, 1954). In view of this it is hard to explain families (such as that in Fig. 6) with normal children born between affected ones.

(2) In many such virus carriers flocculation tests on the serum are abnormal, and in a few abnormalities of liver histology have been shown; in only some such persons is there a past history of an attack of jaundice. Gellis, Craig and Hsia (1954) report their inability to find any abnormality of flocculation 


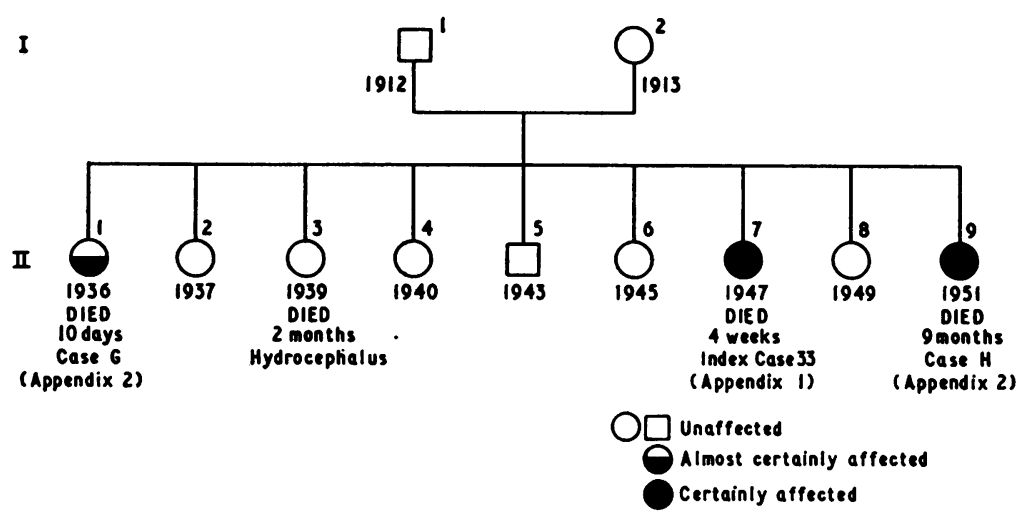

F1G. 6.-Pedigree of the sibship of index Case 33.

tests in the mothers of the cases of 'neonatal hepatitis' in their series.

(3) After administration of serum from an infant who developed 'hepatitis' at 2 months of age: or of that from his mother, volunteers developed hepatitis (Stokes et al., 1954). The onset of the infant's illness was later than usual in the disease we are discussing and necrosis of liver cells was prominent, whereas it is not a feature of our cases.

(4) One mother who had infectious hepatitis at the 32nd week of pregnancy gave birth to a child with ascites and cirrhosis apparent at delivery (Bellin and Bailit, 1952). Again we have not seen such a clinical pattern in this disease but, of course, we cannot deny that it may occur. Of 44 mothers who had hepatitis between the 24th and the 35th weeks of pregnancy, all had normal infants (Hsia, Taylor and Gellis, 1952; Mickal, 1951; Zondek and Bromberg, 1947).

(5) There are several reports of cases (some of families containing several cases) in which evidence is given for suggesting that the mother was a virus carrier. In some this evidence is weak and in most the clinical and/or the pathological features of the disease in the infant differ from the cases we have described (Scott, Wilkins and Kessler, 1954; Beard, 1956; Krainin and Lapan, 1956).

It seems likely that the viruses that cause hepatitis in children and adults do sometimes infect the foetus and damage the liver; however, there is little evidence that they alone cause the entity we have here discussed as 'neonatal hepatitis'. It is possible that the virus could act to determine the manifestation of disease in those foetuses homozygous for the mutant gene which we propose as the main aetiological factor in this disease. Only the development of a method of isolation and culture of these viruses will settle these questions.
The idea of a genetic cause of liver disease is not a new one, for an autosomal recessive gene is basically responsible for Wilson's hepatolenticular degeneration, and Srivastava (1956) has evidence of genetic aetiology in Indian childhood cirrhosis; also such factors seem likely in "congenital hepatic fibrosis' (Kerr, Harrison, Sherlock and Walker, 1961). However, the one feature of genetic action in this disease that will require some explanation is the mechanism by which total recovery may occur in some cases showing gross and typical pathology in infancy. The fact that one child now recovered (No. 14) has parents who are cousins, shows that one cannot claim another non-genetic cause for those who recover. As there is strong evidence of foetal disease it may be that the abnormal genotype determines the absence or the late development of some enzyme that is required by the foetus but not by the infant, and that survival or death is determined by the extent of foetal liver damage. In our cases the outcome is not affected by the birth weight, nor is it related to the severity of the pathological changes in the liver in biopsies taken in infancy. However, as most of the biopsies were taken after 6 weeks of age, they may be of little value in this regard. The possibility that the enzyme defect may be in the placenta (a foetal organ of great importance) must be remembered in future investigations.

\section{Summary}

The diagnostic criteria are presented on which 110 cases of neonatal obstructive jaundice seen over 16 years were classified as extrahepatic biliary atresia (58 cases), intrahepatic biliary atresia (seven cases) or 'neonatal hepatitis' (50 cases including five additional cases without jaundice in the new- 
born period). The natural history of these diseases is described, and it is concluded that only one-third to one-half of cases of 'neonatal hepatitis' recover fully. Familial, clinical and pathological data on those cases whose parents could be traced (47, seven and 4.5 cases respectively) are presented.

It is concluded that there is adequate evidence to show the absence of a familial tendency, of influence of maternal age or of birth order, or of any disturbance of foetal growth in extrahepatic biliary atresia.

In intrahepatic biliary atresia one can only say that 13 cases (our seven with six from the literature) have no affected relatives.

The finding of four consanguineous unions among the parents of the cases of 'neonatal hepatitis' is the basis for suggesting a mutant autosomal gene in homozygous form as the cause of the disease. Even after stringent searching through our index cases to exclude those that might have another cause, only 12 of 71 siblings of index cases were also affected $(p=0.169 \pm 0.044)$. It is suggested that some infants with the genotype for the disease manifest it so mildly or perhaps so severely that the diagnosis is not made. The apparent excess of male over female index cases may be other evidence of failure of manifestation of the genotype. Alternatively our cases may still be of more than one disease.

A marked decrease in birth weight is demonstrated in 'neonatal hepatitis', and seems important confirmation of profound disturbance of liver function in the foetus. It is suggested that the abnormal genotype may determine a deficiency of an enzymatic activity needed by the foetus, but not the infant.

While carrying out the genetic study of these cases one of us (D.M.D.) received a grant from the Royal Children's Hospital, Melbourne, Australia. During this work he learned the techniques and approaches involved from Dr. J. A. Fraser Roberts and Dr. C. O. Carter, and he is especially indebted to them for this training, and for many instructive discussions on this project.

Dr. G. H. Newns has studied the clinical features of these cases and we have had helpful discussions with him. We are indebted to the technical staff of the Department of Morbid Anatomy, especially to Miss Sheila Moore, for the preparation of histological material.
We wish to thank the members of the medical staff of the Hospital for allowing us access to their patients and their records.

\section{REFERENCES}

Ahrens, E. H., Harris, R. C. and MacMahon, H. E. (1951). Atresia of the intrahepatic bile ducts. Pediatrics, 8, 628.

Bailey, N. T. J. (1951a). The estimation of the frequencies of recessives with incomplete multiple selection. Ann. Eugen. (Lond.), 16, 215.

(1951b). A classification of methods of ascertainment and analysis in estimating the frequencies of recessives in man ibid., 16, 223.

Beard, A. G. (1956). Hepatitis in three siblings: Possibility of intrauterine transmission. J. Pediat., 49, 454.

Bellin, L. B. and Bailit, I. W. (1952). Congenital cirrhosis of the liver associated with infectious hepatitis of pregnancy. ibid. 40,60 .

Carter, C. and MacCarthy, D. (1951). Incidence of mongolism and its diagnosis in the newborn. Brit. J. soc. Med., 5, 83.

Craig, J. M. and Landing, B. H. (1952). Form of hepatitis in neonatal period simulating biliary atresia. Arch. Path., 54, 321.

Gellis, S. S., Craig, J. M. and Hsia, D. Y-Y. (1954). Prolonged obstructive jaundice in infancy. IV. Neonatal hepatitis. A.M.A. Amer. J. Dis. Child., 88, 285.

Haas, L. and Dobbs, R. H. (1958). Congenital absence of the intrahepatic bile ducts. Arch. Dis. Childh., 33, 396.

Haldane, J. B. S. (1938). The estimation of the frequencies of recessive conditions in man. Ann. Eugen. (Lond.), 8, 255.

Hsia, D. Y-Y., Boggs, J. D., Driscoll, S. G. and Gellis, S. S. (1958) Prolonged obstructive jaundice in infancy. V. The genetic components in neonatal hepatitis. A.M.A.Amer.J. Dis. Child. component 485 . 95, 485. study on infectious hepatitis during pregnancy. J. Pediat., 41, 13.

Karn, M. N. and Penrose, L. S. (1951). Birth weight and gestation time in relation to maternal age, parity and infant survival. Ann. Eugen. (Lond.), 16, 147.

Ann. Eugen. (Lond.), 16, 147 . Sherlock, $S$ and Walker, $R$. (1961). Congenital hepatic fibrosis. Quart. J. Med., 30, 91.

Krainin, P. and Lapan, B. (1956). Neonatal hepatitis in siblings. J. Amer. med. Ass., 160, 937.

MacMahon, B., Record, R. G. and McKeown, T. (1951). Congenital pyloric stenosis; an investigation of 578 cases. Brit. J. soc. Med., 5, 185 .

Mickal, A. (1951). Infectious hepatitis in pregnancy. Amer. J. Obstet. Gynec., 62, 409.

Neefe, J. R Norris, R. F., Reinhold, J. G., Mitchell, C. B. and Howell, D. S. (1954). Carriers of hepatitis virus in the blood and viral hepatitis in whole blood recipients. J. Amer. med. Ass., 154, 1066.

Scott, R. B., Wilkins, W. and Kessler, A. (1954). Viral hepatitis in early infancy. Pediatrics, 13, 447 .

Smetana, H. F. and Johnson, F. B. (1955). Neonatal jaundice with giant cell transformation of the hepatic parenchyma. Amer. $J$. Path., 31, 747.

Srivastava, J. R. (1956). The genetic factor in infantile cirrhosis of the liver. Indian J. med. Sci., 10, 191.

Stokes, J., Jr., Berk, E. J., Malanut, L. L., Drake, M. E., Barondess, J. A., Bashe, W. J., Wolman, I. J., Farquhar, J. D., Bevan, B., Drummond, R. J., Maycock, W. d'A., Capps, R. B. and Bennett, A. M. (1954). The carrier state in viral hepatitis. J. Amer. med. Ass., 154, 1059.

Sweet, L. K. (1932). Congenital malformation of the bile ducts: a report of three cases in one family. J. Pediat., 1, 496.

Weller, T. H., Macauley, J. C., Craig, J. M. and Wirth, P. (1957). Isolation of intranuclear inclusion producing agents from infants Isolation of intranuclear inclusion producing agents from infants with illnesses resembling cyto

Zondek, B. and Bromberg, Y. M. (1947). Infectious hepatitis in pregnancy. J. Mt Sinai Hosp., 14, 222. 
Appendix I

Affected children in italics; ${ }^{*}=$ Index case; $d .=$ died; sb. = stillborn; F.T. $=38-42$ weeks' gestation.

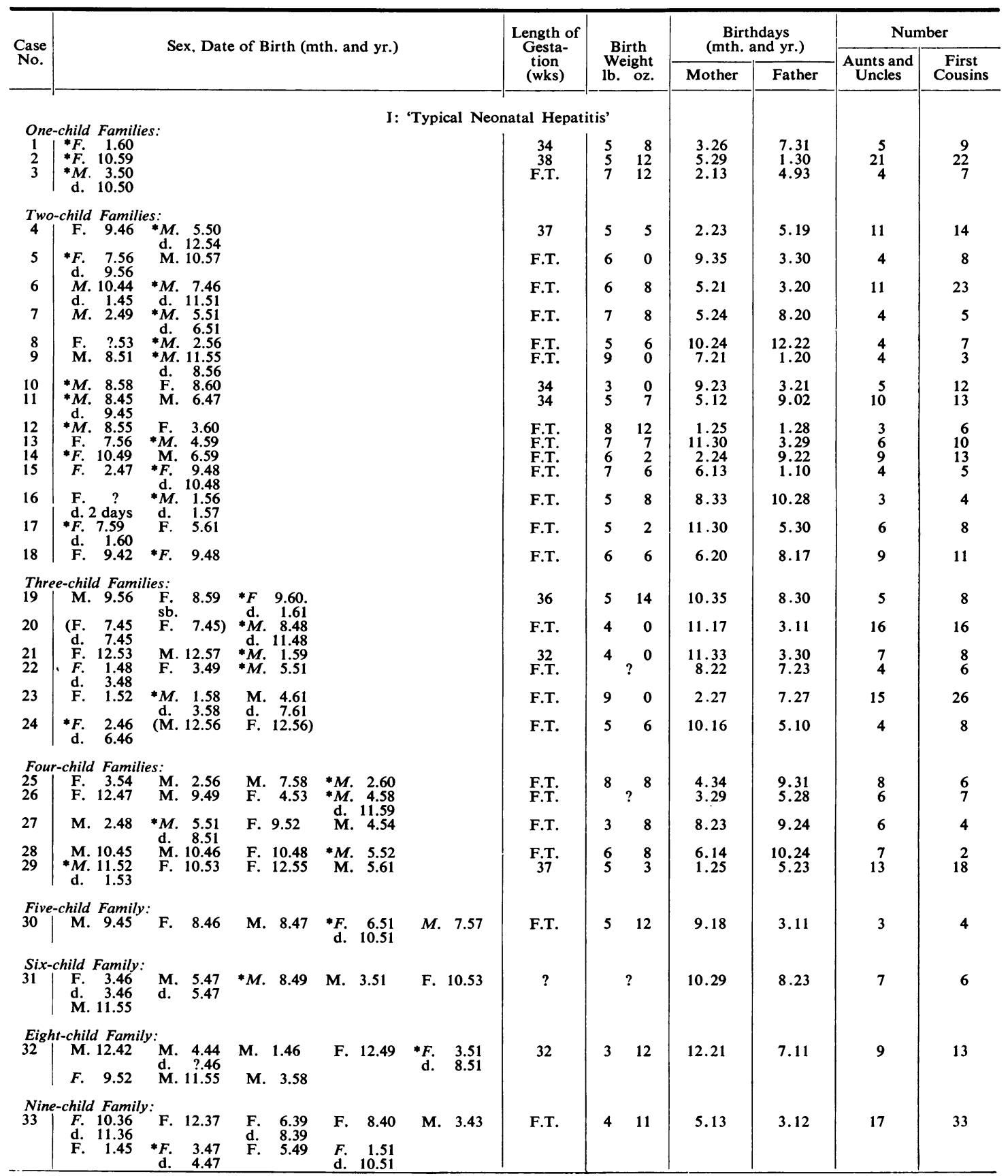


Appendix I continued

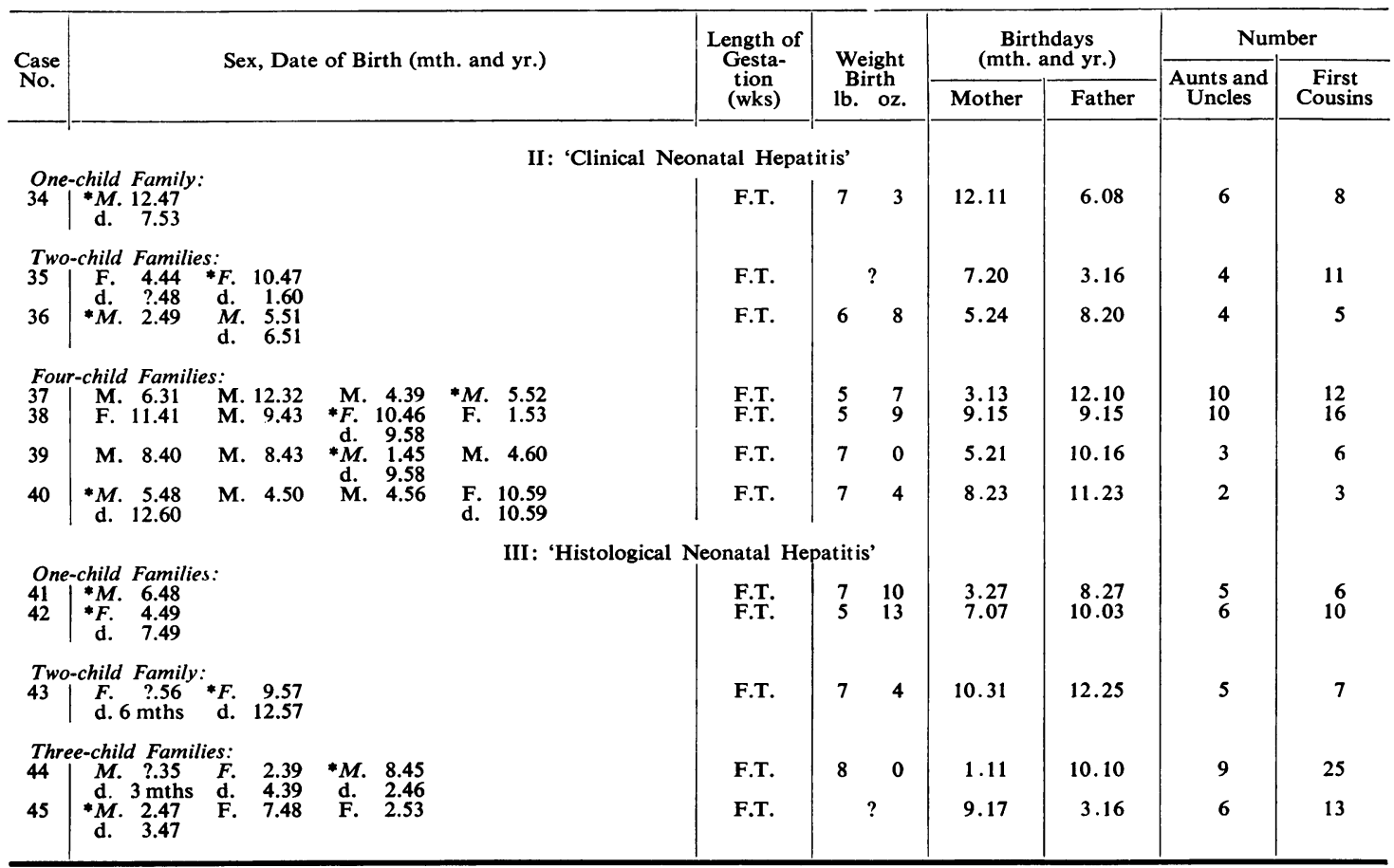

\section{Appendix 2}

\section{Details of Those Siblings of Index Cases of 'Neonatal Hepatitis' Who Have Been Regarded as Affected}

Case A. D.H. Brother of index Case 6, born 1944; birth weight $6 \frac{3}{4} \mathrm{lb}$. $(3,060 \mathrm{~g}$.). Pale stools noted from birth; urine became dark and jaundice developed in the first days of life. Seen at the Children's Department of the General Infirmary, Leeds, at the age of 11 weeks and regarded as 'possibly congenital obliteration of bile-ducts or catarrhal jaundice'. Died at home aged 12 weeks. No autopsy.

Case B. S.L. Born 1949; brother of index Case 7; is index Case 36.

Case C. H.S. Born 1947; sister of index Case 15. Jaundice, pale stools and dark urine present from fourth day of life. Admitted to The Hospital for Sick Children, and a laparotomy at 4 weeks of age showed a small gall-bladder and bile-duct. No biopsy was taken, but a cholecystenterostomy was performed. The jaundice persisted for three months and then faded and she began to thrive. She is now clinically normal with normal liver function tests at the age of 14 years.

Case D. K.H. Born 1948; sister of index Case 22. First child of related parents. Vomiting began at
17 days and was followed by bruising, epistaxis and bleeding from the bowel. These symptoms were the same as those in the index case. Died at home of cerebral haemorrhage at 5 weeks. No autopsy performed.

Case E. W.W. Born 1957; brother of index Case 30. Pale stools were noted in the first week of life and jaundice appeared at 3 weeks of age and persisted for six weeks. He was very ill during this time and was an in-patient in the Babies' Hospital, Royal Victoria Infirmary, Newcastle upon Tyne. Liver function tests were inconclusive. Now, at 4 years, he is clinically normal.

Case F. P.B. Born 1952; sister of index Case 32. Sixth born child, birth weight $4 \mathrm{lb}$. $5 \mathrm{oz}$. (1,955 g.). Admitted to Hammersmith Hospital on the second day of life because of her apparent prematurity. Jaundice appeared on the fifth day of life and persisted until the age of 2 months. No bile pigment could be detected in her stools until 5 weeks of age. Now, at the age of 8 years, clinical findings and liver function test results are normal.

Case G. Born 1936; sister of index Case 33. First born of family, delivered in St. Thomas's Hospital, 
weighing $5 \mathrm{lb} .5 \mathrm{oz}$. (2,408 g.). Umbilical haemorrhage, began on the sixth day of life and resulted in death on the tenth day. There was no evidence of umbilical infection in life or at autopsy which revealed an 'abnormal liver'. No histological report is available.

Case H. J.P. Born 1951. Also a sister of index Case 33. Ninth of the family, born in St. Thomas's Hospital where she remained until her death at 9 months of age. Birth weight was $5 \mathrm{lb}$. $1 \mathrm{oz}$. $(2,295 \mathrm{~g}$.), pale stools were noted on the fifth day of life and jaundice persisted from the tenth day until her death. The clinical diagnosis of neonatal hepatitis was confirmed at autopsy. Sections of the liver have been examined by us and satisfy our criteria.

Case J. B.L. Born 1951. Brother of index Case 36. Is index Case 7.

Case K. Born 1946. Sister of index Case 43. Died at the age of 6 months of cerebral haemorrhage in Royal Victoria Hospital, Brighton. Previously had been healthy. Autopsy revealed 'neonatal hepatitis'-sections were seen by one of us (M.B.) and satisfy our criteria.

Case L. Born 1935; brother of index Case 44. First born of a family of three, all of whom were affected. Fed poorly and failed to gain weight from birth, then developed abdominal distension and died at 3 months of 'marasmus'. No hospital records are available and this description was given by the parents.

Case M. S.C. Born 1939; sister (second born) of index Case 44 and of Case L. Failed to gain weight from birth and, in second month of life, developed vomiting and jaundice and abdominal distension. Laparotomy performed at The Hospital for Sick Children at 2 months revealed cirrhosis of the liver and she died two days later. Autopsy showed the typical histological changes. She is not counted as an index case because of the date of her presentation.
Appendix 3

Details of Causes of Death of Siblings of Index Cases of 'Neonatal Hepatitis', Other Than Those Regarded as Also Affected by the Disease

(1) Sister of index Case 16. Born prematurely (? 6 months' gestation) and weighed $1 \frac{1}{2} \mathrm{lb} .(679 \mathrm{~g}$.). No known cause of prematurity. Died on the second day of life. No autopsy performed. No further details obtainable.

(2) Sister of index Case 19. Stillborn macerated at 8 months' gestation. No autopsy.

(3) Sister of index Case 20. One of like-sex twins, the other of whom has had normal health. It is not accurately known whether this infant was stillborn or died soon after birth. No hospital records available.

(4) Brother of index Case 23. Developed severe diarrhoea at the age of 10 days and was admitted to Queen Elizabeth Hospital, Hackney, where, despite all investigation and therapy, this symptom persisted until his death at 3 months. Autopsy revealed normal liver histology, but is otherwise yet incomplete.

(5) Sister of index Case 31. Born at 7 months' gestation-no reason for prematurity known. Birth weight not known. Died on first day of life. No autopsy performed.

(6) Brother of index Case 31. Born at 32 weeks' gestation-no reason for prematurity known. Birth weight not known. Died at 3 hours of age after being limp from birth. No autopsy.

(7) Brother of index Case 32. Died at the age of 2 years of tuberculous pericarditis.

(8) Sister of index Case 33 (also Fig. 6). Congenital internal hydrocephalus. No evidence of liver disease in life. Died at 2 months of age, but no autopsy.

(9) Sister of index Case 35. Severe mental defect, died at the age of 4 years of pneumonia.

(10) Sister of index Case 40. Fourth child of rhesus negative mother whose serum contained rhesus antibodies. Born in Mayday Hospital, Thornton Heath, after maternal toxaemia and antepartum haemorrhage; pallor and enlarged liver and spleen noted. Coombs' test was positive, haemoglobin $2.9 \mathrm{~g} . / 100 \mathrm{ml}$. and serum bilirubin $2 \cdot 1 \mathrm{mg} . / 100 \mathrm{ml}$. Died at 3 hours of age. No autopsy. 